\section{DIREITO, ORGANIZAÇÕES E AS DIFERENTES REPRESENTAÇÕES SOCIAIS NOS DISCURSOS JURÍDICOS: ADVOCACIA E MAGISTRATURA}

LAW, ORGANIZATIONS AND THE DIFFERENT SOCIAL REPRESENTATIONS IN THE LEGAL DISCOURSES: PRIVACY LAW AND MAGISTRACY
Rafael Lazzarotto Simioni ${ }^{1}$ Jéssica Pereira A. K. Carrozza ${ }^{2}$
RESUMO: Esta pesquisa objetiva analisar as diferentes representações sociais inscritas nas relações entre advocacia privada e magistratura na Região Sul do Estado de Minas Gerais. Através do conceito de organização da teoria dos sistemas sociais autopoiéticos de Niklas Luhmann e da metodologia de explicitação das representações sociais através da Análise do Discurso do Sujeito Coletivo (LEFREVE), esta pesquisa distingue os sistemas de organização de centro e das periferias do direito, em especial, a relação entre magistratura e advocacia privada, para traçar uma distinção entre as representações sociais que uma tem da outra. Como resultado, verifica-se a ocorrência de assimetrias nas relações entre magistratura e advocacia privada, as quais indicam não apenas diferentes formas de produção de sentido do direito no âmbito de cada sistema de organização, como também a existência de relações de poder sobre as formas de ocupação dos espaços jurídicos.

Palavras-chave: Organizações jurídicas. Advocacia privada. Magistratura. Tribunais. Sistema do direito.
ABSTRACT: The intent of this research is to analyze the existing different social representations inside the relations between privacy law and the magistracy in the south of Minas Gerais. Using the concept of organization from the Niklas Luhman's theory of autopoiesis social systems and the methodology of social representation through the collective discourse, this research distinguishes the central organization and the periphery of Law system, special attention to the relations between magistracy and privacy law. As a result, we verify the occurrence of asymmetry into relations between magistracy and privacy law, in wich they do not only indicate distinct ways in the conception of the sense of law inside the scope of each organizational system, but also as the existence of power relations over the ways of Law spaces occupation.

Keywords: Legal organizations. Privacy law. Magistracy. Courts. Legal system.

\footnotetext{
${ }^{1}$ Faculdade de Direito do Sul de Minas. Pós-Doutor em Teoria e Filosofia do Direito pela Universidade de Coimbra; Doutor em Direito Público pela Universidade do Vale dos Sinos; Professor no Programa de Mestrado em Direito da Faculdade de Direito do Sul de Minas e no Programa de Mestrado em Bioética da Universidade do Vale do Sapucaí. https://orcid.org/0000-0002-8484-4491.

${ }^{2}$ Faculdade de Direito do Sul de Minas.. Acadêmica do curso de graduação em direito da FDSM- Faculdade de Direito do Sul de Minas, bolsista de Iniciação Científica do PIBIC/Fapemig. https://orcid.org/0000-0002-7697-5619.
} 


\section{INTRODUÇÃO}

Esta pesquisa objetiva analisar, por meio de uma pesquisa empírica baseada na Análise do Discurso do Sujeito Coletivo (DSC), de Lefreve e Lefreve (2014) e no conceito de sistemas de organização da teoria dos sistemas sociais autopoiéticos de Niklas Luhmann (2005b), as diferentes representações sociais inscritas nas relações entre advocacia e magistratura na Região Sul do Estado de Minas Gerais. Pretende-se explicitar a existência de assimetrias e relações de poder entre sistemas de organização do centro e das periferias do direito, em especial, a relação entre magistratura e advocacia privada, para traçar uma distinção entre a representação social que a magistratura constitui a respeito da advocacia, bem como a da advocacia em relação à magistratura.

A Análise do Discurso do Sujeito Coletivo (DSC) é uma metodologia que permite explicitar as diferentes representações sociais que uma organização jurídica possui em relação às outras. Não se trata de análise de discurso no sentido de Foucault ou de Pêcheux. A DSC é uma metodologia desenvolvida para pesquisas empíricas qualitativas por Lefreve e Levreve (2014) para a explicitação de diferentes representações sociais em diferentes grupos ou, como no caso desta pesquisa, diferentes organizações jurídicas (LUHMANN, 2005a), em especial a magistratura e a advocacia privada.

Na teoria dos sistemas sociais autopoiéticos de Niklas Luhmann, a estrutura do sistema jurídico da sociedade organiza e coloca em operação uma rede complexa de operações de comunicação, dentre as quais, os sistemas de organização. As organizações são as instituições que realizam operações comunicativas do sistema. No âmbito do direito, o sistema de organização central, segundo Luhmann (2005a, p. 213), são os tribunais, cujos membros são formados, em sua parte mais significativa, pela magistratura. Os tribunais constituem o sistema central de organização das decisões jurídicas, diante dos quais todas as demais instituições ocupam os espaços da periferia do sistema jurídico. Advocacia privada, Ministério Público, Delegacias de Polícia, Procuradorias, bem como a Academia, também são sistemas de organização ligados ao direito. Entretanto, tratam-se 
de sistemas periféricos. Isso porque, segundo Luhmann, são os tribunais, e não os periféricos, as organizações que definem o que é e o que pode vir a ser direito.

A questão central desta pesquisa está na verificação da imagem que a advocacia privada e a magistratura constroem reciprocamente uma da outra. Como a advocacia enxerga a magistratura hoje? E como a magistratura enxerga a advocacia? Quais são os problemas e desafios no exercício da profissão que a advocacia atribui à magistratura? $\mathrm{E}$ quais os que a magistratura atribui à advocacia?

Há diversas pesquisas dessa natureza, realizadas tanto por pesquisadores dos Critical Legal Studies norte-americanos, quanto por pensadores das diversas vertentes da teoria social crítica, as quais não podemos reproduzi-las nesta investigação. Tratam-se, no geral, de pesquisas que procuram analisar a prosopografia de importantes atores jurídicos, tais como, ministros dos tribunais superiores, advogados de partidos políticos etc. Estas pesquisas são interessantes e geram resultados críticos significativos, especialmente para se entender as diversas influências políticas e ideológicas que a origem social ou de classe desempenha nos processos de produção de sentido do direito.

Entretanto, esta pesquisa procura seguir um caminho diferente. Nem melhor, tampouco pior. Apenas diferente. Pretende-se analisar, como objeto empírico, não os atores jurídicos, mas as organizações que definem seus membros como atores jurídicos importantes (ROCHA; AZEVEDO, 2012, p. 195). A questão, nesta pesquisa, não está nas influências ideológicas que atuam sob os processos de interpretação, argumentação e decisão jurídica dos atores do direito, mas sim nas influências estruturais que os sistemas de organização desempenham sobre seus membros e não membros.

Para tanto, esta pesquisa utiliza, como metodologia empírica de coleta e organização de dados, a análise do Discurso do Sujeito Coletivo (DSC) (LEFEVRE; LEFEVRE, 2014, p. 504). Através de entrevistas realizadas com membros da organização da magistratura e membros da organização da advocacia privada, a pesquisa organiza os diversos discursos procurando as unidades de fala que constituem os indicadores de discursos coletivos, as identidades organizacionais, as formas de representação social inscritas na estrutura de cada sistema de organização. Como hipótese, espera-se 
demonstrar a existência de diferentes formas de representação social produzidas pela magistratura sobre a advocacia, bem como da advocacia a respeito da magistratura.

Trata-se, portanto, de uma combinação da descrição de Niklas Luhmann (2005b) a respeito dos sistemas de organização do direito, com a metodologia empírica qualitativa da análise do DSC (LEFEVRE; LEFEVRE, 2014, p. 504). Uma combinação entre o conceito de Luhmann a respeito dos diferentes sistemas de organização do direito e as diferentes representações sociais que cada organização jurídica possui uma da outra, em particular, nesta pesquisa, no universo de amostragem de membros da magistratura e membros da advocacia privada da região Sul do Estado e Minas Gerais.

Importante destacar que não se trata da análise do discurso como regime de verdade (Michel Foucault), ou como materialização discursiva (Michel Pêcheux), ou outras noções contemporâneas de discurso. A DSC é uma metodologia de análise empírica, desenvolvida por Lefevre e Lefevre com base na teoria das representações sociais de Moscovici (1978), para a análise de diferentes representações sociais. Esta pesquisa pretende demonstrar, por hipótese, as diferentes representações sociais da magistratura e da advocacia privada, e a existência não só de diferentes formas de produção de sentido do direito em cada sistema de organização, mas também as relações de força entre elas na disputa pela ocupação dos espaços de produção de sentido do direito.

\section{DECISÃO E SISTEMAS DE ORGANIZAÇÃO DO DIREITO}

Seguindo a teoria dos sistemas sociais, especialmente na versão autopoiética de Niklas Luhmann (2005b), o direito não é apenas um conjunto coeso de normas jurídicas válidas em um determinado tempo e território. Tampouco um mecanismo de dominação e reprodução do poder das classes dominantes sobre as dominadas. Entender o direito como sistema significa entendê-lo como uma forma especial de comunicação da sociedade, funcionalmente diferenciada dos demais sistemas sociais, que possui uma estrutura de comunicação altamente especializada para a generalização simbólica de expectativas normativas.

Nessa perspectiva teórica, o estudo dos sistemas é organizado, para fins didáticos, em quatro níveis distintos: o nível mais abrangente do sistema social global; o nível dos 
sistemas sociais parciais ou subsistemas; o nível dos sistemas de organização; e o nível dos sistemas de interação. Máquinas, seres vivos e sistemas de consciência não integram esse nível genuinamente societal dos sistemas sociais, muito embora as relações simbióticas também sejam influenciadas pelas formas de comunicação da sociedade.

O sistema social global é um sistema baseado em comunicação significativa. Onde existe comunicação, existe sociedade. Os limites da sociedade são os limites da comunicação significativa. O sujeito, tal como no pós-estruturalismo francês, não é tão importante para a análise quanto as estruturas, os sistemas de discursividade, o arquivo. Assim também na perspectiva crítica - referimo-nos à tradição da Escola de Frankfurt -, segundo a qual, importante são os atores sociais e não os indivíduos. Mais importante do que o indivíduo, os mecanismos sociais que desencadeiam operações de mudança, transformação e desconstrução das estruturas, na teoria dos sistemas, são os movimentos sociais e as organizações (LUHMANN, 2006, p. 656).

Sistemas sociais parciais ou subsistemas dotados de autopoiese, como o direito, política, economia, arte, religião e ciência, são sistemas de comunicação funcionalmente diferenciados. Possuem estruturas equivalentes, mas funções distintas. São dotados igualmente de códigos, programas, autodescrições e sistemas de organização. Mas as funções que desempenham para a sociedade são diferentes e ligadas a problemas sociais concretos, como são os casos da escassez para a economia, do poder para a política, das expectativas normativas para o direito, a verdade para a ciência ou o transcendente para a religião.

A terceira dimensão dos sistemas sociais é a das organizações. Cada sistema social parcial, dotado de autopoiese, possui um sistema de organização central, responsável pela atualização e organização da rede histórica de comunicação do sistema. As organizações são sistemas de decisão. Elas organizam, através de decisões, a complexidade e a rede histórica de operações do sistema. É o caso dos tribunais para o sistema do direito, os bancos para a economia, os Estados para a política, os templos para a religião, as universidades e centros de pesquisa para a ciência, as galerias de arte e museus para a arte, e as agências de notícias para os meios de comunicação de massa. Segundo Luhmann 
(2006, p. 667), estes são sistemas de organização centrais dos respectivos sistemas sociais parciais.

Entretanto, todo sistema de organização central pressupõe a existência de periferias. Então, a questão é pensar como acontece a relação entre as organizações de centro e as de periferia. Especialmente no caso do direito, no qual não há apenas uma, mas várias organizações periféricas aos tribunais. Por hipótese, é possível observar as advocacias públicas e privadas, bem como a academia, como organizações periféricas do direito, cujas relações não acontecem de modo necessariamente harmônico ou cooperativo. Possivelmente, as relações entre essas diferentes organizações de centro e de periferia do direito estão marcadas por relações de tensão. Tal como no campo da saúde, no qual médicos, enfermeiros, fisioterapeutas e outros estabelecem relações hierárquicas reproduzidas pela própria estrutura das organizações da saúde, também no campo do direito as relações entre magistratura e advocacias não são necessariamente relações lineares e harmônicas entre si.

As decisões realizadas em sistemas centrais e periféricos são diferentes. O referente jurídico pode ser o mesmo, mas a problemática, a orientação teleológica e o horizonte de sentido são diferentes. As advocacias procuram a realização dos interesses dos seus clientes. Procuram a afirmação do direito material na perspectiva dos seus clientes. Já a magistratura possui outro tipo de preocupação, muito mais ligada à qualidade e celeridade da prestação jurisdicional do que ao reconhecimento do direito de uma das partes do processo. Essa diferença de perspectiva, por si só, desencadeia a produção de estruturas de decisão completamente autônomas e diferenciadas entre si (SIMIONI, 2010, p. 128). As quais, uma vez postas em operação, produzem as assimetrias que segregam os membros das organizações de centro e das de periferia.

\section{ANÁLISE DO DISCURSO DO SUJEITO COLETIVO}

Para analisar essa diversidade de perspectivas e horizontes de sentido que se inscrevem nas relações magistratura e advocacia privada, utilizaremos, como uma possível metodologia empírica, a análise do discurso do sujeito coletivo. 
O Discurso do Sujeito Coletivo (DSC) é uma técnica desenvolvida no fim da década de 1990, por Lefevre e Lefevre (2000), a partir da teoria das representações sociais de Moscovici (1978). Ele é um método de resgate da Representação Social (RS) por reconstituir e compartilhar o modo como são "metabolizadas" por uma sociedade, um grupo ou uma organização (LEFEVRE; LEFEVRE, 2014, p. 504). A RS está sempre presente em uma opinião, posicionamento, manifestação ou postura de um indivíduo em sua vida cotidiana. Ou seja, a Representação Social é o reconhecimento do senso comum como conhecimento, na visão de seus autores.

As representações sociais são fenômenos complexos. Esta é uma abordagem feita pela ciência contemporânea, fundamental para a compreensão de fenômenos em diversos campos do conhecimento através da necessidade de interação entre sistemas. O estudo da complexidade não está ligado somente ao conhecimento do conteúdo das partes, mas à soma deste com o reconhecimento da relação desses sistemas com o ambiente. Ou seja, entender os fenômenos sociais pressupõe contextualizar esses fenômenos individuais com a estrutura social.

Conhecer as RSs é um ato de atribuição de sentido, é um processo de descrição e reconstituição. Pressupõe ações, opções e decisões que envolvem o processamento da informação e que resultará no pensamento de uma coletividade. Metodologicamente, ao utilizar a técnica do Discurso do Sujeito Coletivo, faz-se com que as Relações Sociais fiquem bastante próximas das opiniões como elas de fato são.

Os DSCs são opiniões individuais transformadas em produtos cientificamente tratados, mantendo, porém, as características reconhecíveis da fala cotidiana. Esse resultado é descrito como "uma reconstrução do pensamento coletivo como produto científico" (LEFEVRE; LEFEVRE, 2014, p. 504). Portanto, o objetivo do Discurso do Sujeito Coletivo é atribuir ao sujeito discursivo a possibilidade de, ao mesmo tempo, ser capaz de falar o conteúdo da Relação Social e, ser por ela, falado.

Esta pesquisa teve como universo de amostragem magistrados e advogados privados atuantes na Região Sul do Estado de Minas Gerais, com a participação de 5 magistrados e 4 advogados privados. Para a análise do DSC, esse número de entrevista constitui um universo de amostragem representativo do âmbito de aplicação da pesquisa. 


\section{O DISCURSO COLETIVO DA MAGISTRATURA}

Seguindo essa metodologia da análise do DSC, foram realizadas cinco entrevistas com magistrados do Sul de Minas, para os quais foram apresentadas perguntas abrangentes e potencialmente disparadoras dos processos de construção das representações sociais, estruturadas na forma de dois eixos: "o que você acha do ensino jurídico hoje?"; e "o que você acha da relação entre juízes e advogados?"

A intenção das perguntas foi oportunizar a produção discursiva das diferentes formas de representação que uma organização jurídica tem em relação à outra, em especial, nesta pesquisa, a representação da organização da advocacia privada no imaginário da magistratura.

Para tanto, como introdução ao diálogo estabelecido, a pesquisa utilizou uma pergunta de abertura, relacionada à visão que a magistratura possui da formação dos bacharéis em direito no Brasil, de modo a estabelecer uma primeira conexão com as RS da magistratura em relação à advocacia.

Realizando a leitura dos depoimentos, tornou-se possível identificar os seguintes indicadores de RS da magistratura a respeito da advocacia.

O que você acha do ensino jurídico hoje?

De um modo geral, eu vejo o ensino jurídico deficiente, especialmente pela baixa exigência e rigor das faculdades de direito. Pode-se explicar por conta do elevado número de faculdades de direito, e nós sabemos que uma instituição exigente pode ocasionar perda de alunos.

O ensino jurídico hoje, para mim, está de muita baixa qualidade, e eu acho que é em razão da pulverização das faculdades de direito pelo Brasil. Eu acho que houve uma banalização do curso de direito. Ao mesmo tempo que foi uma democratização do acesso, houve uma banalização do conhecimento, e isso fez com que a qualidade do ensino jurídico tenha baixado.

A gente lança no mercado mais advogados do que o mercado absorveria no exercício da função. É claro que nem todo mundo que se forma no direito tem a intenção de atuar na área, mas se todos eles que formam no curso jurídico quisessem realmente atuar, o mercado de trabalho não absorveria todos.

Eu acredito que, o que é importante não é a quantidade de cursos jurídicos, mas sim a qualidade do curso.

O que você acha da relação entre juízes e advogados? 
Nunca tive desavença pessoal com qualquer advogado. Em um primeiro momento eu lembro que o advogado atua para uma das partes e, portanto, ele tem interesse direto no resultado do processo, o que o magistrado não tem.

A gente deve respeitar a função de cada um no processo. $O$ advogado tem a função de ajuizar a ação, produzir provas e defender o direito de seu cliente, e o juiz tem a função de decidir.

Essa relação deve ser desarmônica na medida em que expressam pontos de vistas diferentes. O estabelecimento da tese de um com a tese do outro, que levará à uma tese final. Isso é necessário. Se cada profissional respeitar as funções de um e de outro no processo, eu acredito que nunca vai ter atrito profissional entre juízes e advogados.

A minha relação com o advogado é de colega de trabalho. Sempre foi assim, desde o início. Nunca modifiquei. Nunca tive problemas com ninguém. Nos meus quase cinco anos como juiz, foram raros os problemas com advogados porque, em via de regra, o respeito é recíproco.

\section{DISCURSOS PERIFÉRICOS: A PERSPECTIVA DA ADVOCACIA}

Foram realizadas, assim como com os magistrados, entrevistas com 4 (quatro) advogados que atuam no Sul de Minas e em especialidades diversas, para os quais foram apresentadas as mesmas perguntas citadas anteriormente, estruturadas nos seguintes vetores: "o que você acha do ensino jurídico hoje?" e "o que você acha da relação entre juízes e advogados?".

A intenção das perguntas também foi disparar diferentes formas de representação que uma organização jurídica tem em relação à outra. Desta vez, buscou-se a representação social que a organização da advocacia privada tem em relação à magistratura.

Analisando-se as repostas e, seguindo a metodologia da análise do DSC, esta investigação alcançou os seguintes indicadores:

O que você acha do ensino jurídico hoje?

Eu percebo uma mudança de perspectiva, de paradigma. As faculdades de direito estão segmentadas. Algumas estão mais voltadas para a área acadêmica e teórica, algumas outras estão mais voltadas para o concurso público, e poucas preparam o profissional para ser advogado de carreira.

Hoje o ensino jurídico está muito pulverizado. Existem muitas instituições e nem todas com o compromisso de seriedade no ensino, que está muito sucateado, muito voltado para um negócio. Como as faculdades estão sendo abertas sem nenhum critério, elas não estão preocupadas em contratar bons professores, mestres e doutores, mas sim em cobrar a mensalidade. 
A gente está tendo uma convergência no sentido de que o sucesso é através do concurso público. Está havendo uma automação desse aluno para decorar leis. Quando você começa a trabalhar só com uma vertente, você não o prepara para aquela que foi excluída. E nem todos conseguem. Aí a pessoa tem que virar advogado, mas sem nenhuma noção.

Hoje está se perdendo o foco na questão de que é possível ter sucesso advogando. Geralmente nós ouvimos falar da dificuldade da advocacia, que advogar é difícil. Mas as outras áreas também são difíceis.

\section{O que você acha da relação entre juízes e advogados?}

Esse é um tema polêmico. É muito difícil ser imparcial na hora de tratar desse tema. Às vezes é uma relação conflituosa porque, juízes que não tiveram experiencia como advogados, não conseguem imaginar o que é estar do outro lado. Ele é uma pessoa que muitas vezes usa o cargo ou posição para se colocar em um patamar diferente, e isso é uma percepção ruim, porque atrapalha o processo e o diálogo que precisa existir.

A nossa Constituição fala que não existe diferença hierárquica nessa relação. Mas, infelizmente, na prática não é assim que acontece. Alguns juízes ainda insistem em ter um "ar" de superioridade, de destratar o advogado. Tem que ser uma linha reta porque, na verdade, nesse trio processual, existem os advogados, o Ministério Público e o juiz. É preciso que exista esse entendimento, que é constitucional, de que não existe diferença hierárquica, já que essa relação ainda é bastante injusta.

Eu já estive numa situação em que o juiz ameaçou conceder guarda unilateral para uma das partes sendo que não havia esse pedido e, às vezes, para conduzir as partes para um acordo que ele queria, que fosse melhor para o que ele estava pretendendo. Eles não têm que adiantar argumentos de sentença. Eles não têm que usar isso para tentar fazer um acordo ou não. Toda vez que eu tentava argumentar, ele nos tratava com uma falta de educação imensa. Na prática, tem juiz que grita, que acusa a gente de estar mentindo. Já recebi voz de prisão em audiência por interromper testemunho. Eu já me senti envergonhada de um juiz chamar a atenção ou ser grosseiro com algum colega meu, de chamar a atenção dele na minha frente.

Eu já tive experiencia de juízes que apontaram supostos erros no meu serviço na frente do meu cliente. $\mathrm{O}$ advogado tem uma posição perante o cliente dele. Então você ostenta uma posição perante o seu cliente. Você faz sua petição e contestação com base nos argumentos que você acredita que serão os melhores para defender os seus interesses e, de repente, o juiz está te desautorizando na frente daquele que te contratou.

Eu já atuei na região toda, e também em muitas cidades pequenas. Aqui na nossa região, é a minoria, mas, infelizmente, essa minoria é exagerada ao não ser legal, ao ser superior. A postura deles é bem exacerbada. A gente fala isso na região toda. Mas, ao analisarmos, é principalmente nas comarcas menores que estão concentrados os juízes que se acham deuses.

O pensamento é o seguinte: se eu, que não preciso julgar, consigo tratar um processo e uma audiência de uma forma mais humana e digna, por que o juiz, que está ali justamente para julgar e entender a verdade das coisas, não consegue? Antigamente tínhamos juízes que tratavam bem, com urbanidade, eram 
humanos, eram pessoas que estavam ali, não como justiceiros, mas como julgadores.

Alguns juízes agem com abusos, como "eu que mando aqui", "eu vou te prender". Os juízes que já foram advogados, antes de serem juízes, entendem melhor a situação. Parece que eles não têm a necessidade de querer impor a sua posição ou o seu argumento. $O$ juiz tem todo um aparato em torno de sua função, ele tem condição de debater com alguém sem ter que bater na mesa e dizer "quem manda aqui sou eu". A relação é mesmo de respeito e de atenção com esses juízes que a gente consegue perceber que estão efetivamente se importando com a solução do problema, e não em criar um outro.

Eu quero que ele compreenda o meu cliente, que ele compreenda as características do meu cliente, e que ele compreenda que ele não é mais do que eu nessa relação.

\section{RELAÇÕES DE PODER E AS DIFERENTES FORMAS DE OCUPAÇÃO DOS ESPAÇOS SIMBÓLICOS DO DIREITO}

Os resultados dos DSCs da magistratura e advocacia permitem estabelecer, dentre outras coisas, uma reflexão importante sobre a prática jurídica contemporânea: a existência de assimetrias entre os diferentes sistemas de organização do direito. Por um lado, a magistratura, como organização centralizada nos tribunais, que segundo Luhmann (2005a, p. 212) constituem o centro do sistema jurídico, constrói e reproduz um imaginário a respeito da advocacia privada baseado na harmonia de relações, no coleguismo e na inexistência em geral de conflitos ou disputas de qualquer natureza.

Por outro lado, a advocacia privada, como organização periférica do sistema, constrói e reproduz outro imaginário a respeito da magistratura: um imaginário baseado em uma relação autoritária, de submissão e coerção. As entrevistas foram realizadas com apenas quatro membros da organização da advocacia privada, na cidade de Pouso Alegre (MG), mas a consistência e a recorrência desse imaginário tornam interessante conjecturar a possibilidade, em futuras pesquisas, de generalização desses resultados em nível nacional.

Essa assimetria entre as diferentes representações sociais permite, dentre outras coisas, observar três consequências imediatas: a) magistratura e advocacia privada são sistemas de organização muito diferentes, orientados a objetivos e padrões de racionalidade diferentes, que b) transformam a ideia tradicional de unidade do direito em uma ideologia, uma construção imaginária que esconde a diversidade de perspectivas 
absolutamente contingentes entre o direito da magistratura e o direito da advocacia; c) nessa assimetria entre magistratura e advocacia privada pode ser observado um processo de apropriação da episteme do direito, de modo exclusivo, pela magistratura, isto é, um jogo de forças que, hoje, se desenha forma de um processo de ocupação, pela magistratura, de todos os espaços de produção de sentido do que é e do que pode vir a ser direito.

Diferentemente da área da saúde, na qual há cursos de graduação específicos para as diferentes organizações da saúde (medicina, enfermagem, psicologia, fisioterapia, farmácia etc.), o direito manteve por muito tempo o imaginário de que, por se tratar de uma mesma e única faculdade ou curso de graduação para todas as organizações jurídicas (magistratura, advocacia privada, advocacias públicas, delegacias de polícia, academia), haveria uma certa unidade do direito, independentemente da diversidade de sistemas de organização. Há uma tradição secular muito forte que escondeu o fato de que cada organização jurídica possui e desenvolve um imaginário diferente a respeito do direito.

As funções são diferentes, com diferentes racionalidades, diferentes formas de ver o mesmo direito. Os textos de referência são os mesmos: as legislações, contratos, constituição, precedentes. Mas os sentidos que se constroem a partir desses sistemas simbólicos de referência são absolutamente diferentes e guiados por diferentes formas de racionalidade. Por muito tempo se pensou que a diferença entre o ensino jurídico nas faculdades de direito e a prática do direito nas instituições jurídicas fosse um problema de diferença entre teoria e prática. Na verdade, cada organização reconstrói um sentido diferente da própria relação entre teoria e prática. Estamos afirmando que há uma prática acadêmica, outra prática advocatícia e outra prática jurisdicional sobre o mesmo direito. Práticas jurídicas diversas que transformam a relação entre teoria e prática no interior de cada organização jurídica.

A advocacia trabalha na perspectiva da realização do direito material dos seus clientes. Enquanto a magistratura trabalha na perspectiva da prestação jurisdicional do melhor modo possível (SIMIONI, 2011, p. 129). Essa diferença de perspectivas, por si só, já é suficiente para colocar em marcha uma série de pressupostos discursivos diferentes, os quais constroem uma imagem diferente a respeito do mesmo referente jurídico. A leitura 
que os advogados fazem do direito é diferente da leitura que os magistrados fazem do mesmo direito. E isso constitui um obstáculo a qualquer pretensão teórica de racionalizar ou de criar modelos de interpretação, argumentação e decisão jurídica baseados em pressupostos de unidade do direito. Essa diversidade de perspectivas significa, também, que não apenas as organizações desempenham operações e formas de comunicação diferentes, mas sobretudo que o próprio direito se produz de modo diferente no âmbito de cada uma dessas organizações. Do mesmo modo que na área da saúde a medicina, enfermagem, psicologia, fisioterapia farmácia etc. constroem um imaginário diferente a respeito do que é e do que pode vir a ser saúde, também no campo jurídico o direito é reconstruído de modo diferente dependendo do sistema de organização do qual se é membro.

Se realmente existe essa diversidade de perspectivas, de processos de construção imaginária da realidade jurídica dentro de cada sistema de organização, então pode-se verificar também a existência de relações de força ou de disputa entre as organizações pela imposição de um imaginário em detrimento dos outros possíveis. O fato de que a advocacia, para a magistratura, constitui uma atividade profissional "parceira", geralmente harmônica e sem conflitos demonstra logo a posição central que essa organização, a magistratura, ocupa dentro dos quadros dos tribunais. Diferentemente da advocacia, que no geral se sente sob uma relação de submissão ou de um tipo qualquer de inferioridade em relação à magistratura.

Essa assimetria sinaliza a existência de uma relação hierárquica entre as organizações da magistratura e da advocacia privada, segundo a qual a magistratura exerce um controle praticamente exclusivo sobre a episteme do direito. Controlar a episteme do direito significa o poder de dizer o que é o que pode vir a ser direito. 0 controle da episteme é diferente de uma disputa teórica, conceitual ou paradigmática (SIMIONI, 2017, p. 168). Não se trata de uma disputa sobre os critérios que definem o direito válido, mas sim uma disputa sobre o que é direito. A luta pela episteme do direito não está no nível, geralmente acadêmico, sobre qual conceito de direito deve prevalecer ou sobre qual teoria ou paradigma deve guiar os critérios de correção e verdade da prática 
jurídica, mas sim no nível da positividade do direito de dizer o que é e o que pode vir a ser direito.

Há uma apropriação da episteme do direito pela magistratura que, no âmbito dos tribunais, passou a prescindir do trabalho da advocacia como uma referência importante para a tomada de decisões jurídicas. Diferentemente da primeira metade do século XX, a advocacia privada, hoje, não possui mais o poder de definir o que é e o que deve vir a ser direito. Suas discussões se deslocaram da esfera política, da liderança política que exerceu até meados do século XX e hoje se limita a uma preocupação comercial e a esforços de qualidade na prestação de serviços. A liderança política na definição da episteme do direito, isto é, a ocupação dos espaços de produção de sentido do direito, hoje, é exercida, exclusivamente, pela magistratura.

Os impactos dessas três consequências são enormes: no campo do ensino jurídico, a orientação aos concursos públicos e à lógica de reprodução correta dos saberes jurídicos dogmáticos se encontra suplantando e sufocando os processos de ensino e aprendizagem críticos, inovadores e orientados à emancipação. O símbolo do sucesso não está mais ligado ao exercício de uma liderança política emancipatória na comunidade - se é que alguma vez foi -, mas à aprovação em exames de concursos públicos que não exigem inovação, crítica e transformação, mas justamente o contrário: reprodução de saberes dogmáticos, incluindo, como se também fosse direito, o entendimento jurisprudencial de alguns tribunais superiores. A resposta correta do "juiz Hércules", metáfora da hermenêutica política de Ronald Dworkin, no Brasil, não está nos princípios de moralidade política da nossa comunidade; não está nas convicções que revelam a maior virtude do nosso direito: está, na verdade, no gabarito das empresas contratadas para a realização dos concursos públicos, guiados pela apropriação jurisprudencial do direito.

Importante perceber que, até meados do século XX, não era a magistratura, mas sim a advocacia que exercia o controle e domínio da episteme do direito brasileiro. Boa parte das lideranças políticas da época eram da advocacia. Grande parte dos professores e pesquisadores do direito eram advogados. A carreira de professor de direito como profissão autônoma e exclusiva é uma experiência recente na cultura jurídica brasileira. E talvez seja justamente essa perspectiva genuinamente acadêmica que permite observar, 
sob um ponto de vista externo, as diferenças entre as organizações da magistratura e da advocacia, bem como as relações de poder que entre elas se instauraram neste século.

\section{CONSIDERAÇÕES FINAIS}

O fato das diferentes profissões ou carreiras jurídicas serem, historicamente, formadas por uma mesma e homogênea faculdade de direito ocultou a existência de especificidades, assimetrias e relações de força entre os diferentes sistemas de organização do direito. Os indicadores das representações sociais dos profissionais membros da advocacia privada e da magistratura demonstram existir não apenas diferentes formas de ocupação dos espaços de produção de sentido do direito, mas também relações de poder na ocupação desses espaços. Relações sob as quais, atualmente, a magistratura reproduz, através de referências a si mesma e seus precedentes, sua doutrina e seu modo de ver o mundo, uma organização hierárquica que se reflete inclusive sobre a academia.

Se esses resultados, que foram obtidos exclusivamente com membros das organizações da advocacia privada e da magistratura em Pouso Alegre (MG), puderem ser generalizados em uma perspectiva mais abrangente, isso pode significar uma transformação significativa no modo de se entender a circularidade crítica na relação entre teoria e prática. Isso porque, diferentemente das críticas tradicionais da sociologia ou da ciência política ao bacharelismo no Brasil e à conexão entre as elites políticas do século XX ao direito, na verdade o que está acontecendo hoje é um deslocamento dos centros de liderança política, da advocacia privada, para a magistratura.

Obviamente há advogados e sociedades de advogados muito poderosos, especialmente aqueles, como lembrava Pierre Bourdieu (2006, p. 214), que atuam no ou próximo ao Estado. Os advogados dos grandes partidos políticos geralmente se tornam ministros dos tribunais superiores quando seus partidos conquistam o poder. Mas ressalvadas essas situações, a advocacia privada, hoje, perdeu a liderança política que exerceu durante o século XX. Sua doutrina, seu pensamento, seu modo de ver o mundo não constitui mais a referência dominante na episteme do direito. Concursos públicos e até mesmo a academia se encontram submetidos à reprodução da visão exclusiva da 
magistratura. Até mesmo as teorias dominantes hoje no campo do direito processual e da hermenêutica jurídica, como é o caso incrível da ponderação, são teorias que só fazem sentido no âmbito da prestação jurisdicional, não fazem sentido nem no ensino do direito, tampouco no da realização do direito material dos clientes.

Uma objeção crítica importante que pode ser feita a esses resultados é o fato de que, independente do sistema de organização da advocacia ou da magistratura, os profissionais estariam igualmente reproduzindo um único e mesmo sistema de dominação, a mesma "superestrutura" de dominação das classes, o mesmo mecanismo de racionalidade técnica e instrumental que coloniza o mundo da vida, o mesmo sistema ideológico de controle, organização e normalização dos valores do capitalismo em detrimento dos valores da emancipação social.

Entretanto, essa visão universalizante do direito oculta justamente as diferenças que existem entre o ensino jurídico na academia, o trabalho de afirmação do direito material dos clientes na advocacia e a prestação jurisdicional pela magistratura nos tribunais. Na perspectiva da teoria dos sistemas de Niklas Luhmann (2005a), o direito em si mesmo não é nada além de um sistema de comunicação que generaliza simbolicamente expectativas normativas. Ele separa o que é lícito e o que é ilícito, o que é direito e o que não é direito. As decisões sobre o que será conectado no lado do direito ou no do não direito são realizadas no âmbito dos sistemas de organização. Por isso que, dependendo do sistema de organização que ocupa a posição central nessa rede histórica de decisões, as formas de produção de sentido do direito ficam sob o comando da estrutura da organização do centro. Na periferia só há oposição, resistência ou submissão.

Se nosso diagnóstico estiver correto, torna-se importante pensar em uma reestruturação democrática das organizações jurídicas no Brasil. Uma democracia interorganizacional, um espaço democrático capaz de transformar a relação de submissão entre organizações centrais e periféricas em relações de cooperação. Não se trata de uma mera questão normativa de prerrogativas e competências constitucionais. As relações entre magistratura e advocacia ultrapassaram os limites do normativo e se encontram, hoje, inscritas na estrutura de poder que comanda os processos de produção de sentido do direito. 


\section{REFERÊNCIAS}

BOURDIEU, Pierre. O poder simbólico. 9. ed. Tradução de Fernando Tomaz. Rio de Janeiro: Bertrand Brasil, 2006.

LEFREVE, Fernando; LEFEVRE, Ana Maria Cavalcanti. Discurso do sujeito coletivo: representações sociais e intervenções comunicativas. Texto Contexto Enferm, Florianópolis, v. 23, n. 2, p. 502-50, abr./jun. 2014.

LUHMANN, Niklas. El derecho de la sociedad. Tradução de Javier Torres Nafarrate, Brunhilde Erker, Silvia Pappe e Luis Felipe Segura. México DC: Universidad Iberoamericana e Herder Editorial, 2005.

LUHMANN, Niklas La sociedad de la sociedad. Tradução de Javier Torres Nafarrate. Mexico: Herder, 2006.

LUHMANN, Niklas Organizzazione e decisione. Tradução de Giancarlo Corsi. Milano: Bruno Mondadori, 2005.

MOSCOVICl, S. A representação social da psicanálise. Rio de Janeiro, Zahar, 1978.

ROCHA, Leonel Severo; AZEVEDO, Guilherme de. Notas para uma teoria da organização da decisão jurídica autopoiética. Revista de Estudos Constitucionais, Hermenêutica e Teoria do Direito (RECHTD), v. 4, n. 2, p. 193-213, jul./dez. 2012.

SIMIONI, Rafael Lazzarotto. Conhecimento e poder: reflexões sobre as relações entre academia e judiciário no Brasil. Cadernos de Direito, v. 17, n. 33, p. 157-185, jul./dez. 2017.

SIMIONI, Rafael Lazzarotto. Direito processual e sociologia do processo: aproximações entre estrutura social e semântica do direito processual na perspectiva da teoria dos sistemas de Niklas Luhmann. Curitiba: Juruá, 2011. 